\title{
Potential Analysis of Inefficient Garden Land and Residual Forest Land Remediation in Comprehensive Land Remediation of the Whole Region-A Case Study of Zhemu Town, Guilin City, China
}

\author{
Mingyuan Liu, Xiangwen Cai, Yuening Song, Yan Zhao, Zehao Liu \\ School of Earth Sciences, Guilin University of Technology, Guilin, China \\ Email: 563970082@qq.com, 598196224@qq.com, 1315643664@qq.com,648088245@qq.com, 330364913@qq.com
}

How to cite this paper: Liu, M. Y., Cai, X. W., Song, Y. N., Zhao, Y., \& Liu, Z. H. (2021). Potential Analysis of Inefficient Garden Land and Residual Forest Land Remediation in Comprehensive Land Remediation of the Whole Region-A Case Study of Zhemu Town, Guilin City, China. Journal of Geoscience and Environment Protection, 9, 79-90.

https://doi.org/10.4236/gep.2021.910006

Received: September 22, 2021

Accepted: October 19, 2021

Published: October 22, 2021

Copyright $\odot 2021$ by author(s) and Scientific Research Publishing Inc. This work is licensed under the Creative Commons Attribution International License (CC BY 4.0).

http://creativecommons.org/licenses/by/4.0/

\section{(c) (i) Open Access}

\begin{abstract}
The remediation of inefficient garden land and defective forest land is one of the important sources and types of supplementary cultivated land in the comprehensive land remediation of the whole region. The remediation and development of inefficient garden land and defective forest land will effectively alleviate the multiple pressures faced by cultivated land at present. Taking Zhemu Town, Guilin City, China as an example, on that basis of the data of the third national land survey, using analytic hierarchy process, this paper selects six evaluation factors, including water source, traffic, slope, field concentration, farmland infrastructure and villagers' will, to study the remediation potential of inefficient garden land and defective forest land in Zhemu Town, and delimits four potential divisions, in order to provide the basis for the arrangement of land remediation projects in Zhemu Town. The results show that the northern, central and western regions of Zhemu Town have great remediation potential.
\end{abstract}

\section{Keywords}

Analytic Hierarchy Process, Inefficient Garden, Defective Forest Land, Potential Analysis, Comprehensive Improvement of Land in the Whole Region

\section{Introduction}

Comprehensive land improvement in the whole region can effectively protect 
cultivated land resources, realize centralized contiguous cultivated land, and thus carry out large-scale management of rural cultivated land, accelerate the pace of agricultural modernization, improve rural ecological environment, and promote the development and construction of green villages in China, which plays a vital role in the coordinated development of urban and rural areas in China. The remediation of inefficient garden land and defective forest land is one of the important remediation types in the comprehensive land remediation of the whole region, the research on the remediation potential of inefficient garden land and defective forest land can effectively broaden the ways of supplementing cultivated land, provide strong support for solving the problem of balance between occupation and compensation of cultivated land (Liu, 2020), and have extremely important significance for promoting the scientific development of land resources in China and improving the use value of land resources. At present, there are many researches on the analysis of land remediation potential (Zheng et al., 2018; Yan \& Cheng, 2019; Yang et al., 2013; Ding, 2017; Cao \& Li, 2016), for example, Li Quanbao (2019) discussed the key problems and suggestions in the development of garden land and defective forest land as new cultivated land sources on the basis of exploring the development practice of garden land and defective forest land ( $\mathrm{Li}, 2019)$, Jiang Changsheng (2018) explored some methods about the development of remediation potential of garden land and defective forest land, which provided methodological guidance for the analysis of remediation potential of inefficient garden land and defective forest land (Jiang, 2018). Li Quanbao (2016) focused on the problems encountered in the actual development of garden land and defective forest land, while Jiang Changsheng (2018) only studied the technical methods needed for the development of garden land and defective forest land. Neither scholar discussed the problems and methods together. In this paper, analytic hierarchy process is used to analyze the remediation potential of inefficient garden land and defective forest land in Zhemu Town, not only the technical methods but also the remediation potential were studied, it is suggested that the local people's government can make reasonable arrangements for the land remediation project in Zhemu Town with reference to the analysis results and the wishes of the villagers, so as to contribute to improving the income of the villagers in Zhemu Town, promoting the coordinated development of economy, society and ecology in the project area, and realizing the rural revitalization strategy in China.

\section{General Situation of Study Area}

\subsection{Location and Natural Environment of the Study Area}

Zhemu Town is located in the southern suburb of Guilin, in the northern part of Yanshan District, Zhemu Town has a subtropical climate, heavy rainfall is mainly concentrated in summer, the annual average precipitation is about $1894 \mathrm{~mm}$, the sunshine time is long, the annual average sunshine number is about 1550 hours, the climate is mild, the annual average temperature is about $19^{\circ} \mathrm{C}$, and $\mathrm{Zhemu}$ 
Town faces the river and Lijiang River from northwest to southeast, its tributary Xiangsi River flows through Zhemu Town from southwest, and there is Baizhujing Reservoir in the south, which is rich in water resources. Zhemu Town is a typical karst area, mainly composed of limestone strata. The territory is mainly plain, with a small number of hills distributed in the east. The terrain is low in the east and north, high in the southeast, and the highest point is the top of the middle and east hills, with an altitude of about 400 meters. Details are shown in Figure 1.

\subsection{Current Situation of Land Use}

According to the data of the third national land survey, Zhemu Town has a total

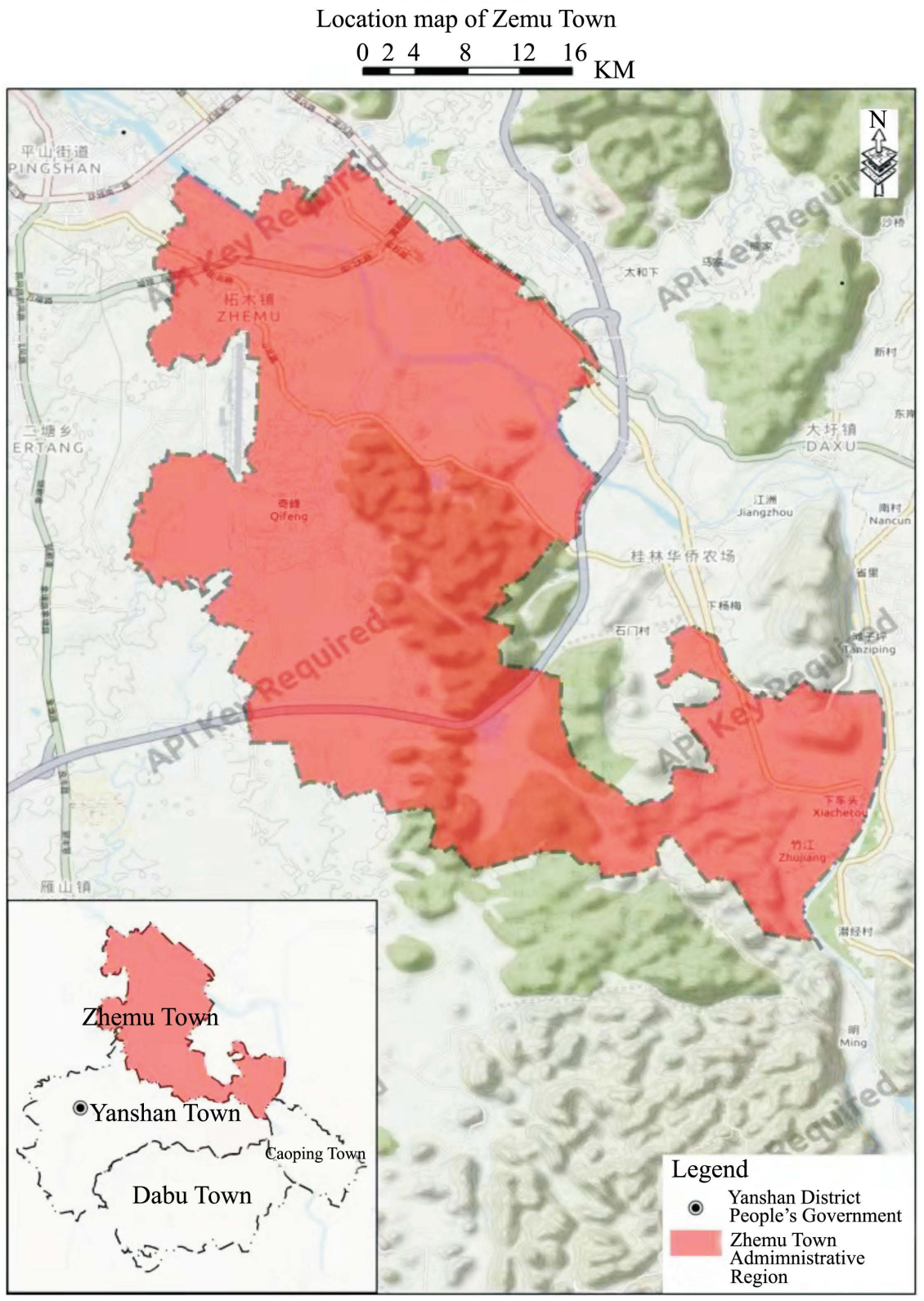

Figure 1. Location map of Zhemu Town. 
of 8633.65 hectares of land. Among them, the area of cultivated land is 1595.78 hectares, accounting for $18.48 \%$ of the total land area of Zhemu Town; the area of the garden is 941.47 hectares, accounting for $10.90 \%$; the area of forest land is 3438.40 hectares, accounting for $39.83 \%$. Details are shown in Figure 2.

\section{Research Methods and Data Processing}

\subsection{Research Methodology}

Analytic Hierarchy Process (AHP) is selected to determine the weight of potential evaluation index of inefficient garden land and defective forest land. Analytic Hierarchy Process (AHP) is a decision-making method that decomposes the elements always related to decision into objectives, criteria, schemes and other levels, and carries out qualitative and quantitative analysis on this basis (Huang et al., 2012; Liu et al., 2013; Peng \& Jiang, 2020; Chen \& Cao, 2019). Combined with the actual situation of Zhemu Town, we collected relevant data and referred to the existing literature (Lu et al., 2020; Jiang et al., 2012; Deng, 2018; Fan, 2019; Shang, 2020; Ji, 2018; Wang et al., 2017).

\subsection{Data Processing}

The process of data processing is shown in the following flowchart (Figure 3).

\subsection{Potential Evaluation Process}

1) Evaluation module

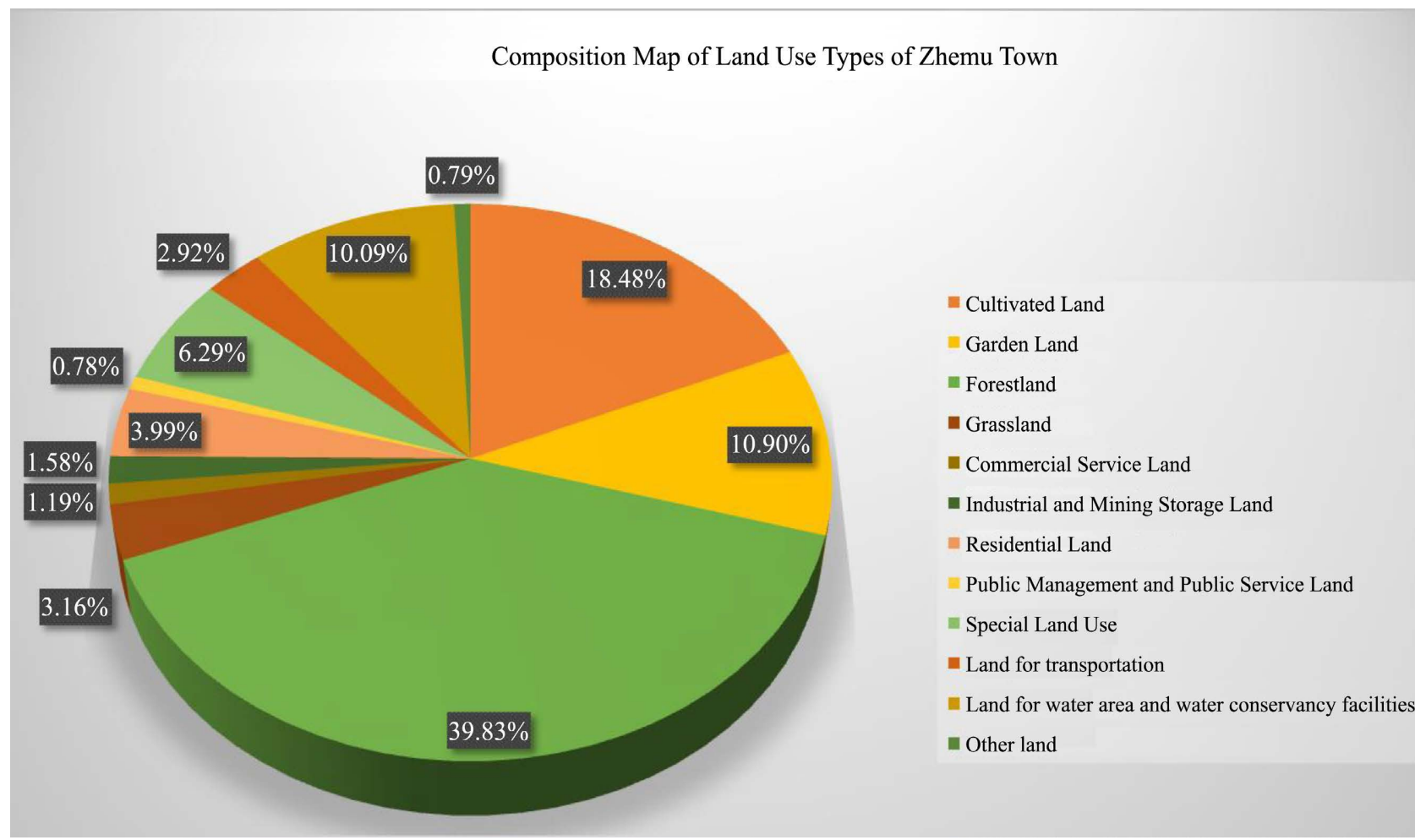

Figure 2. Land use status quo of Zhemu Town. 


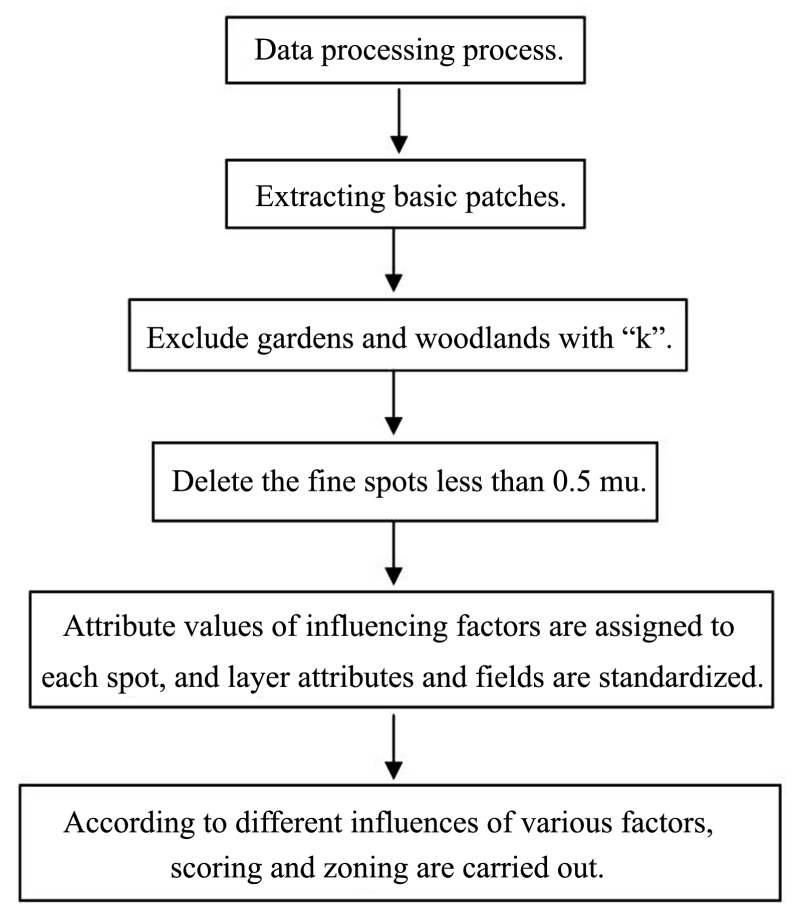

Figure 3. Flow chart of data processing.

The remediation potential map spot of inefficient garden land and defective forest land in Zhemu Town was taken as the evaluation unit.

2) Evaluation index and weight

On the basis of the actual situation of land resources characteristics in Zhemu Town and drawing lessons from Yan Jing's (2015) selection of evaluation factors in the article "Evaluation of Land Remediation Potential in Nibo Town, Xide County", finally, selected water source, traffic, slope, field concentration, farmland infrastructure, villagers will of six factors as low-efficiency garden and defective forest land remediation potential evaluation indicators to analyze.

Each evaluation factor is divided into different grades according to the actual situation of Zhemu Town. Following the principle that the higher the grade, the higher the score, each evaluation factor is given the highest grade of 100 points and the lowest grade of 0 points. At the same time, according to the different influence degrees of each evaluation factor on the evaluation of land remediation potential, different weights are given, and the sum of each weight is equal to 1 . The weight of each factor is shown in Table 1 below.

3) Standardized treatment of evaluation indicators

ArcGIS 10.3 software is used to standardize the evaluation index of remediation potential of inefficient garden land and defective forest land. The specific process is shown in Table 2 below.

The score of villagers' wishes is based on widely listening to the needs and wishes of villagers and adopting a unified standardized score of 85 points according to the actual engineering construction.

4) Calculation formula of remediation potential 
Table 1. Weight table of potential evaluation index of defective forest land in inefficient garden land.

\begin{tabular}{ccccccc}
\hline Factor & Water source & Traffic & Slope & Degree of field concentration & Farmland infrastructure & Villagers' will \\
\hline Weight & 0.2 & 0.15 & 0.2 & 0.15 & 0.15 & 0.15 \\
\hline
\end{tabular}

Table 2. Evaluation factor assignment table of remediation potential.

\begin{tabular}{|c|c|c|c|c|c|}
\hline $\begin{array}{l}\text { Evaluation factor } \\
\text { Evaluation factor } \\
\text { Standardized score }\end{array}$ & $80-100$ & $60-80$ & $40-60$ & $20-40$ & $0-20$ \\
\hline Water source & $\begin{array}{l}\text { It is distributed } \\
\text { around the river, } \\
\text { and the water } \\
\text { source conditions } \\
\text { are very abundant }\end{array}$ & $\begin{array}{l}\text { Around the reservoir, } \\
\text { it is convenient to use } \\
\text { water and the water } \\
\text { source conditions } \\
\text { are sufficient }\end{array}$ & $\begin{array}{l}\text { There are ponds, } \\
\text { potholes and low } \\
\text { water storage, and } \\
\text { the water resources } \\
\text { conditions are average }\end{array}$ & $\begin{array}{l}\text { It is far away from } \\
\text { the water source, } \\
\text { only sporadic } \\
\text { potholes are low, and } \\
\text { the water resources } \\
\text { are insufficient }\end{array}$ & - \\
\hline Traffic & $\begin{array}{l}\text { Roads, railways, } \\
\text { waterways and other } \\
\text { traffic roads pass by, } \\
\text { and the traffic is } \\
\text { very convenient }\end{array}$ & $\begin{array}{l}\text { There are roads, } \\
\text { field paths, etc., } \\
\text { and the traffic is } \\
\text { more convenient }\end{array}$ & $\begin{array}{l}\text { There are field paths } \\
\text { passing by near the } \\
\text { highway, and the } \\
\text { traffic conditions } \\
\text { are average }\end{array}$ & $\begin{array}{l}\text { It is far away from } \\
\text { the highway, } \\
\text { scattered in the } \\
\text { field paths, and } \\
\text { the traffic is poor }\end{array}$ & $\begin{array}{l}\text { There is no road and } \\
\text { it is far away from } \\
\text { the transportation } \\
\text { road, and the traffic } \\
\text { conditions are } \\
\text { very poor }\end{array}$ \\
\hline Slope & $\leq 2$ & $2-6$ & $6-15$ & $15-20$ & $20-25$ \\
\hline $\begin{array}{l}\text { Degree of } \\
\text { field concentration }\end{array}$ & $\begin{array}{l}\text { Each field is } \\
\text { concentrated and } \\
\text { distributed in a } \\
\text { large area, and the } \\
\text { concentration } \\
\text { degree is very high }\end{array}$ & $\begin{array}{l}\text { The fields are } \\
\text { concentrated and } \\
\text { distributed, and the } \\
\text { degree of } \\
\text { concentration } \\
\text { is high }\end{array}$ & $\begin{array}{l}\text { Some fields are } \\
\text { concentrated and } \\
\text { distributed }\end{array}$ & $\begin{array}{l}\text { The concentrated } \\
\text { distribution of } \\
\text { fields is small and } \\
\text { the concentrated } \\
\text { area is small }\end{array}$ & $\begin{array}{l}\text { The fields are scat- } \\
\text { tered and not concen- } \\
\text { trated }\end{array}$ \\
\hline $\begin{array}{l}\text { Farmland } \\
\text { infrastructure }\end{array}$ & $\begin{array}{l}\text { Farmland } \\
\text { infrastructure } \\
\text { such as ditches and } \\
\text { main canals are } \\
\text { widely distributed } \\
\text { around the field, } \\
\text { and the farmland } \\
\text { infrastructure } \\
\text { conditions are } \\
\text { very good }\end{array}$ & $\begin{array}{l}\text { The farmland } \\
\text { infrastructure } \\
\text { around the field is } \\
\text { relatively perfect, } \\
\text { and the farmland } \\
\text { infrastructure } \\
\text { conditions } \\
\text { are better }\end{array}$ & $\begin{array}{l}\text { A small amount of } \\
\text { farmland } \\
\text { infrastructure is } \\
\text { distributed around } \\
\text { the field, and the } \\
\text { farmland } \\
\text { infrastructure } \\
\text { conditions are } \\
\text { general }\end{array}$ & $\begin{array}{l}\text { Farmland infrastruc- } \\
\text { ture is scattered } \\
\text { around the field, and } \\
\text { the condition of farm- } \\
\text { land infrastructure is } \\
\text { poor }\end{array}$ & $\begin{array}{l}\text { There is no farmland } \\
\text { infrastructure distri- } \\
\text { bution or occasional } \\
\text { distribution around } \\
\text { the field }\end{array}$ \\
\hline Villagers' will & - & - & - & - & - \\
\hline
\end{tabular}

The calculation formula of remediation potential score is as follows:

$$
S i=P i * W i
$$

In which $S i$ refers to the score value of remediation potential, $P i$ refers to the value of each evaluation index, and Wi refers to the weight of each index relative to the target layer.

Total land remediation potential score $S$ is the sum of remediation potential scores of all evaluation factors, and the calculation formula is as follows:

$$
S=\sum S i
$$

Therefore, the higher the score, the greater the potential of land remediation. 
5) Classification of remediation potential

According to the final score, the remediation potential is divided into firstclass potential area, 70 - 80 second-class potential area, 60 - 70 third-class potential area and less than 60 fourth-class potential area, so as to analyze the remediation potential of inefficient garden land and defective forest land in Zhemu Town.

\section{Results and Analysis}

\subsection{Potential and Analysis of Inefficient Garden Remediation}

Inefficient gardens refer to some gardens with low output due to extensive utilization. It is not only necessary but also urgent to renovate inefficient orchards. By selecting suitable crops and improving planting methods according to local conditions, the output of orchards can be effectively improved, and it is also conducive to improving the living standards and happiness of local villagers.

Using ArcGis10.3 analysis and calculation, the total area of remediation area of low-efficiency garden in Zhemu Town is 785.62 hectares, of which the first-class potential area covers an area of 394.19 hectares, accounting for $50.17 \%$ of the total area of remediation area of low-efficiency garden; The secondary potential area covers an area of 305.65 hectares, accounting for $38.91 \%$; the third-level potential area covers an area of 61.84 hectares, accounting for $7.87 \%$; the fourth-level potential area covers an area of 23.94 hectares, accounting for 3.05\%. The remediation potential of low-efficiency garden in Zhemu Town is mainly the first-class potential area and the second-class potential area, while the third-class potential area and the fourth-class potential area are small (see Table 3).

From the potential distribution map of inefficient garden in Zhemu Town (left in Figure 4), it can be seen that the primary and secondary potential areas of remediation potential in Zhemu Town are concentrated, mainly distributed in the central and western parts of Zhemu Town and the southeast, and sporadically distributed in the northern region; the third and fourth potential areas are mainly distributed in the south of Zhemu Town and a few in the southeast.

The reason for this situation is that the Lijiang River passes through the north of Zhemu Town, the Xiangsi River, a tributary of the Lijiang River, flows through the central and western parts of Zhemu Town from northeast to southwest, and there is Baizhujing Reservoir in the southeast, which makes the water

Table 3. Regionalization potential area of low efficiency garden in Zhemu town.

\begin{tabular}{ccc}
\hline Potential zoning & Area (in hectares) & Proportion \\
\hline the first level potential area & 394.19 & $50.17 \%$ \\
secondary potential arer & 305.65 & $38.91 \%$ \\
tertiary potential area & 61.84 & $7.87 \%$ \\
four-level potential area & 23.94 & $3.05 \%$ \\
\hline
\end{tabular}



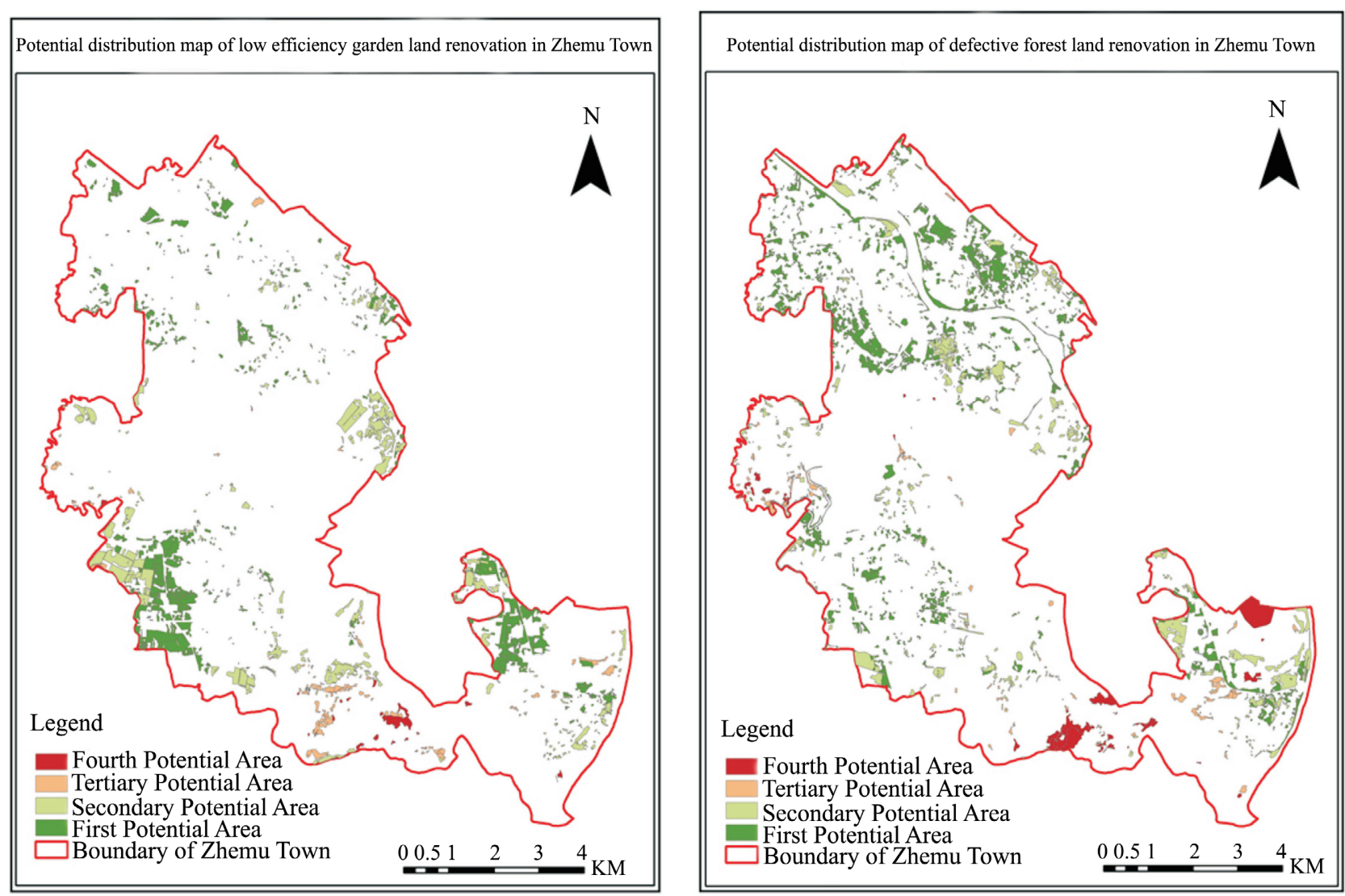

Figure 4. Distribution map of remediation potential of inefficient garden land and defective forest land in Zhemu Town.

resources in the north, central and western parts of Zhemu Town abundant; moreover, the farmland infrastructure in the central and western parts of Zhemu Town is relatively perfect and the traffic conditions are good, and the slope in the central and western parts of Zhemu Town is relatively low, which makes the inefficient garden remediation potential in the central and western parts of Zhe$\mathrm{mu}$ Town great; because the distribution of inefficient gardens in northern China is less, the first and second potential areas are only sporadic; the steep slope in the middle and east of Zhemu Town makes the renovation potential of inefficient garden in the middle and east of Zhemu Town small. It is suggested that the government of Zhemu Town can refer to the research results and combine the wishes of local villagers to scientifically arrange inefficient garden remediation projects, and should focus on remediation of inefficient gardens in the central, western and southeastern regions of Zhemu Town.

\subsection{Potential and Analysis of Remediation of Defective Forest Land}

Defective forest land refers to forest land which is destroyed by natural or human intervention, with low coverage rate, low economic value and low ecological value. The development and remediation of defective forest land will effectively improve the quality of local cultivated land, enhance the economic value of 
land, increase the income of villagers, and maintain and adjust the local ecological environment.

According to the analysis and calculation of ArcGis10.3, the total area of remediation area of residual forest land in Zhemu Town is 1002.94 hectares, of which the first-class potential area covers 554.27 hectares, accounting for $55.27 \%$ of the total area of remediation area of residual forest land; the secondary potential area covers an area of 289.65 hectares, accounting for $28.88 \%$; The third-level potential area covers an area of 54.88 hectares, accounting for 5.47\%; the fourthlevel potential area covers an area of 104.14 hectares, accounting for $10.38 \%$. The largest potential area of low-efficiency garden remediation in Zhemu Town is the first-class potential area, followed by the second-class potential area, the fourth-class potential area again, and the third-class potential area is the smallest (see Table 4).

From the potential distribution map of defective forest land in Zhemu Town (Figure 4, right), it can be seen that the primary and secondary potential areas of remediation potential in Zhemu Town are concentrated, mainly distributed in the northern, central and western regions of Zhemu Town and the southeast region; the third-level potential areas are scattered in Zhemu Town, while the fourth-level potential areas are mainly distributed in the south and southeast border areas of Zhemu Town.

The reason for this situation is that the Lijiang River passes through the north of Zhemu Town, Xiangsi River, a tributary of Lijiang River, flows through the central and western parts of Zhemu Town from northeast to southwest, there is Baizhujing Reservoir in the southeast, which makes the water resources in the north, midwest and southeast of Zhemu Town abundant. In addition, in the north, central and western regions of Zhemu Town, the farmland infrastructure is relatively perfect, the traffic accessibility is good, the slope in the central and western regions is relatively low, and the distribution of residual forests in the northern region is relatively concentrated, which makes the first-class potential area in the north of Zhemu Town the widest distribution and the greatest remediation potential, followed by the central and western regions and the southeast region; the southern and central eastern parts of Zhemu Town have a large slope and high terrain, which makes the remediation potential of the defective forest land in the central and eastern parts of Zhemu Town small. In the southeast boundary of Zhemu Town, it is mainly a four-level potential area with small remediation potential due to its far distance from the water source and large

Table 4. Regionalization potential area of defective forest land in Zhemu town.

\begin{tabular}{ccc}
\hline Potential zoning & Area (in hectares) & Proportion \\
\hline the first level potential area & 554.27 & $55.27 \%$ \\
secondary potential arer & 289.65 & $28.88 \%$ \\
tertiary potential area & 54.88 & $5.47 \%$ \\
four-level potential area & 104.14 & $10.38 \%$ \\
\hline
\end{tabular}


slope. It is suggested that the government of Zhemu Town can refer to the research results and combine the wishes of local villagers to scientifically arrange the remediation projects of defective forest land, and should focus on the remediation of defective forest land in the north, central and western regions of Zhemu Town, especially the defective forest land concentrated in the north.

\section{Conclusion}

At present, scholars pay more attention to and study the potential of land remediation, but they mainly focus on the potential of agricultural land remediation, which provides a good research method for guiding the development of land remediation potential. The innovation of this paper lies in relying on the research carried out under the background of global comprehensive improvement and under the guidance of rural revitalization strategy, which is different from the traditional research on the improvement potential of agricultural land, but detailed to the comprehensive improvement potential of inefficient gardens and defective woodlands in agricultural land, and using the research method of Yan Jing (2015) as a reference, adopting analytic hierarchy process to study the land improvement potential of inefficient gardens and defective woodlands in Zhemu Town. It not only fills the study on the remediation potential of single inefficient garden and incomplete forest land, but also provides some reference significance for the subsequent study on inefficient garden and incomplete forest land.

Under the background of comprehensive land remediation, combined with analytic hierarchy process, the remediation potential of inefficient garden land and defective forest land in Zhemu Town was obtained. In Zhemu Town, compared with the remediation area of inefficient garden, the remediation area of defective forest land has more remediation advantages and the remediation potential is higher than that of inefficient garden. According to the potential analysis results of the final inefficient garden land and defective forest land, relevant departments and local governments can focus on rectifying the inefficient garden land and defective forest land with great potential in the north, central and western regions and southeast regions of Zhemu Town. Further strengthen the management and remediation of land in Zhemu Town, actively guide the masses to participate, and fully explore the potential of local land comprehensive remediation.

Through the development and renovation of inefficient gardens and defective forest land in Zhemu Town, the cultivated land area in Zhemu Town will be increased to a great extent, and the income of local villagers, their satisfaction with life and their personal happiness index will be improved; it is also conducive to promoting the scientific allocation and flow of land elements in Zhemu Town and promoting the comprehensive improvement of fields, water, roads, forests and villages in the project area; promote the planning and development of comprehensive land improvement in the whole local area, and then promote the 
coordinated development of urban and rural areas in China, and accelerate the realization of rural revitalization strategy in China.

\section{Conflicts of Interest}

The authors declare no conflicts of interest regarding the publication of this paper.

\section{References}

Cao, C. L., \& Li, P. (2016). Analysis of Land Remediation Potential in Nanhu District of Jiaxing City. Southern Agriculture, 10, 92-94.

Chen, M., \& Cao, Z. H. (2019). Study on Comprehensive Benefit Evaluation of Land Improvement Projects Suitable for Mechanization in Hilly and Mountainous Areas-Based on Improved AHP-Fuzzy Comprehensive Evaluation Method. Journal of Chinese Agricultural Mechanization and Chemistry, 40, 145-151.

Deng, Z. Y. (2018). Evaluation of Agricultural Land Remediation Potential in Wanzhou District of Chongqing. Southwest University.

Ding, Y. Q. (2017). Analysis of Land Remediation Potential of Rural Residential Areas in Laohekou City. Central China Normal University.

Fan, L. J. (2019). Study on the Potential and Model of Rural Land Remediation-A Case Study of Tongxin County, Ningxia. Ningxia University.

Huang, H. L., Wu, C. F., \& Zhang, S. Z. (2012). Benefit Analysis and Evaluation of Land Remediation Planning in Heilongjiang Province. Journal of Agricultural Engineering, $28,240-246$.

Ji, Z. K. (2018). Risk Analysis of Land Regulation Project Based on Fuzzy Analytic Hierarchy Process. Project Management Technology, 10, 57.

Jiang, C. S. (2018). Analysis on the Technical Methods of Investigating the Reclamation Potential of Garden Land and Defective Forest Land in Guangxi. Construction Engineering Technology and Design, No. 23, 627.

Jiang, Y. B., Hu, S. G., Liu, Y. Y., \& Wang, Z. Q. (2012). Comprehensive Evaluation of Sustainable Cultivated Land Consolidation Potential in Hilly and Mountainous Areas Based on GIS. Land Science of China, 26, 42-47, F0003.

Li, Q. B. (2019). Study on Key Problems in the Development of Garden Land and Defective Forest Land-Taking Xinyi City as an Example. China Land and Resources Econo$m y, 32,53-58,88$.

Liu, L. (2020). The Realization Path of Holistic Land Remediation: Theoretical Framework and Case Study. Zhejiang University.

Liu, S. Y., Yang, Q. Y., He, C. Y., Wang, X., \& Hou, P. (2013). Benefit Evaluation of Land Remediation Based on Analytic Hierarchy Process (AHP) and Fuzzy Comprehensive Evaluation Method-An Empirical Study of Rural Land Remediation in 26 Villages in 3 Districts and Counties of Chongqing. China Agronomy Bulletin, 29, 54-60.

Lu, S. H., Zhu, J. L., Zhou, J. X., Tian, S. C., Wang, Y. R., \& Chang, J. (2020). Ecological Benefit Evaluation of Land Remediation from the Perspective of Ecological Landscape. Research on Soil and Water Conservation, 27, 311-317.

Peng, L. W., \& Jiang, Q. J. (2020). Social Benefit Evaluation of Land Remediation Project Based on Analytic Hierarchy Process-Taking Lijiazhai Town as an Example. Rural Economy and Technology, 31, 48-51.

Shang, J. (2020). Study on Comprehensive Benefits of Yan'an Land Improvement Project 
Based on Analytic Hierarchy Process. Agricultural Sciences, 10, 395-402.

https://doi.org/10.12677/HJAS.2020.106059

Wang, Y., Sun, Y. Y., \& Zhang, H. K. (2017). Comprehensive Benefit Evaluation of Land Rectification Based on Analytic Hierarchy Process and Fuzzy Comprehensive Evaluation Method-Taking Xiayukou Land Rectification Project in Hancheng as an Example. Agriculture and Technology, 37, 10-14, 32.

Yan, B. H., \& Cheng, H. (2019). Analysis of Land Remediation Potential in Baicheng City. Research on Land and Natural Resources, No. 2, 1-2.

Yan, J. (2015). Evaluation of Land Remediation Potential in Nibo Town, Xide County. Chengdu University of Technology.

Yang, W., Xie, D. T., Liao, H. P., Pan, Z., Zhu, L., \& Li, T. (2013). Potential Analysis of Agricultural Land Remediation Based on High-Standard Basic Farmland Construction Mode. Journal of Agricultural Engineering, No. 7, 219-229.

Zheng, R. Z., Cai, X. W., Liu, M. H., Shao, Y., Zhong, S. J., \& Chen, D. L. (2018). Potential Analysis and Practical Application of Agricultural Land Remediation in Yangshuo County. Southern Land and Resources, No. 1, 49-51. 